\title{
Signal Control for Oversaturated Intersections Using Fuzzy Logic
}

\author{
Lin Zhang \\ Ph.D. Candidate \\ Department of Civil and Environmental Engineering \\ University of Hawaii at Manoa \\ 2540 Dole Street, 383, Honolulu, HI 96822 \\ Honglong Li, Ph.D. \\ Project Engineer \\ Lyon Associates, Inc. \\ 841 Bishop Street, Suite 2006 \\ Honolulu, HI 96813 \\ Panos D. Prevedouros, Ph.D.* \\ Associate Professor \\ Department of Civil and Environmental Engineering \\ University of Hawaii at Manoa \\ 2540 Dole Street, 383, Honolulu, HI 96822 \\ Telephone: (808) 956-9698 \\ Fax: (808) 956-5014 \\ E-mail: pdp@hawaii.edu
}

Submitted for consideration for presentation at the 2005 Annual Meeting of the TRB and publication in the Transportation Research Record

Honolulu, Hawaii

July 12, 2004

Revised: November 11, 2004

${ }^{*}$ Corresponding Author

Paper Length

4,860 words in text

2,250 words in 9 exhibits

7,110 words total $(\max =7500)$ 


\begin{abstract}
The fuzzy logic controller (FLC) presented in this paper simulates the control logic of experienced human traffic controllers such as police officers who supersede signal controls at over-saturated intersections during special events. Given real-time traffic information, the FLC controller decides on whether to extend or terminate the current green phase based on a set of fuzzy rules. A new microscopic simulator, the Intersection Control Simulator (ICS), was developed to facilitate the evaluation of the proposed FLC strategy. The FLC strategy was compared with pretimed and actuated control strategies using a typical intersection with varying traffic volume levels. Based on delay, speed, \% stops, time in queue and throughput-to-demand ratio statistics, the FLC strategy produced significant improvements over pretimed and actuated control strategies under heavy traffic volumes. This indicates that FLC has the potential to improve operations at over-saturated intersections. Comparisons with other traffic signal control strategies, evaluation with common simulation software and expansion of the FLC for application to arterials are planned.
\end{abstract}




\section{INTRODUCTION}

Intersections are common bottlenecks in roadway systems. More intelligent traffic signal control would make the current roadway system operate more efficiently without building new roadways or widening existing roadways which is often impossible due to scarce land availability and public opposition to roadway expansion in many locations. It has been recognized that signal improvement is one of the most useful and cost-effective methods to reduce congestion (1).

Most signal controls are implemented with either pretimed controls or actuated controls. A pretimed controller repeats preset signal timings derived from historical traffic patterns. An actuated controller computes phase durations based on real-time traffic demand obtained from the detection of passing and stopped traffic on all lanes leading into an intersection.

Actuated control has an efficiency handicap rooted to its simple operating principle of phase extension until a preset maximum is reached. Thus, a single vehicle arrival prolongs the green and cycle length for the whole intersection without regard for the traffic conditions on all other approaches with a red signal. The performance of actuated control is superior to that of pretimed control at low to medium volumes because of its ability to respond to variable arrivals on each approach. However, its performance deteriorates under heavy traffic conditions as it extends green phases to the maximum green times on all phases when high traffic volumes occur on all approaches (2). Given that maximum greens are set in order to contain delays and cycle lengths within acceptable levels, the "maxed-out" operation at congested intersections defaults the actuated controller into a mediocre pretimed controller. This results in degraded intersection performance when efficiency is required the most (2).

Adaptive control is designed to take account of the traffic conditions for the whole intersection. It has the ability to adjust signal phasing and timing settings in response to real-time traffic demands at all or some approaches. Several methods have been developed for designing adaptive control systems and $\mathrm{Li}$ $(3,4)$ categorized them as optimization-based, rule-based, and optimization and rule-based control strategies. The current research focus for intersection control is on the application of artificial intelligence techniques such as expert systems, neural networks, and fuzzy logic.

Current control methods typically cannot accommodate heavy or highly uneven traffic well. Human control logic may be superior to existing signal control logic because of its ability to realize the prevailing traffic demands. For example, police officers often replace signal control when an intersection is unusually over-saturated, e.g., during arrivals to and departures from a sports arena or popular concert, during major Marathon races in U.S cities, during large parades, etc. This paper explores the potential application of fuzzy logic on traffic signal control under over-saturated traffic conditions.

The next section presents a summary of applications of fuzzy logic in traffic control operations. The summary of past research findings leads to the objectives of this study. Then, the principles of fuzzy 
sets and fuzzy logic are discussed followed by the methodology of the research presented herein. The simulation tool, Intersection Control Simulator (ICS), and a case study are presented next, followed by our conclusions.

\section{LITERATURE REVIEW}

The first known attempt to apply fuzzy logic in traffic control was made by Pappis and Mamdani (5). They simulated an isolated signalized intersection composed of two one-way streets with two lanes in each direction without turning traffic. The fuzzy controller reduced average vehicle delay compared to an actuated controller.

Kelsey and Bisset (6) also simulated a simple two-phase signal control of an isolated intersection with one lane on each approach. The fuzzy logic control performed better than both pretimed and actuated control especially when the traffic flow between different directions was highly uneven.

Niittymaki and Pursula (7) also simulated an isolated intersection. They found that fuzzy logic controller lead to shorter vehicle delay and lower \% stops especially when the traffic volume was heavy.

Trabia, Kaseko and Ande (8) designed a fuzzy logic controller for a signalized intersection with left-turning traffic. Traffic volumes and queue lengths counted by detectors were used in a two-stage fuzzy logic algorithm to determine whether to extend or terminate the current signal phase. Fuzzy logic control lead to an average of $9.5 \%$ decrease in delay and $1.3 \%$ reduction in stops compared to actuated control.

Niittymaki and Kikuchi (9) developed a fuzzy logic algorithm for controlling a pedestrian crossing signal. Through microscopic simulation they found that their fuzzy logic algorithm provided at least equal or better performance than conventional actuated signal control.

Chen, May and Auslander (10) studied a fuzzy logic controller for freeway ramp metering. Their model was applied to the Bay Bridge with simulation. The fuzzy logic controller was able to reduce congestion as well as efficiency losses due to incidents.

Nakatsuyama, Nagahashi, and Nishizuka (11) applied fuzzy logic to control two adjacent intersections on an arterial with one-way movements. Fuzzy control rules were developed to determine whether to extend or terminate the green signal for the downstream intersection based on the upstream traffic.

Chiu (12) pioneered fuzzy logic to control multiple intersections in a network of two-way streets with no turning movements. Fuzzy rules were used to adjust cycle time, phase split and offset parameters. Those adjustments to the signal cycle length and splits were made based on the degree of saturation on each intersection approach. The proposed method was tested with simulation and the results showed that fuzzy logic control reduced average delay significantly. 
All the aforementioned research concepts were tested with simulation. Few field tests of fuzzy logic control have been conducted to date. In 2001, Niittymaki (13) presented a field test of a simple twophase fuzzy signal controller. The results showed that the fuzzy logic controller performed better than vehicle-actuated control in terms of delay, \% stops and savings in fuel and emissions.

\section{STUDY OBJECTIVE}

The research reviewed above generally reported a better performance of fuzzy logic controllers compared to pretimed and actuated controllers. However, most of the reviewed research involved either one-way streets or intersections without turning movements. In addition, fuzzy rules were determined mostly by traffic conditions on the subject approaches without taking into account the traffic conditions on competing approaches. Furthermore, previous research did not develop appropriate fuzzy rules for leftturning vehicles.

Fuzzy logic is suitable for controlling intersections, especially for those with heavy traffic. This is because fuzzy logic is able to emulate the control logic of police officers directing traffic who sometimes replace signal control when the intersection is unusually congested.

This study has two objectives:

1. Design a fuzzy logic algorithm to control over-saturated intersections of two-way streets with leftturning movements.

2. Evaluate the fuzzy logic algorithm and compare it with pretimed control and actuated control using microscopic simulation.

\section{FUZZY SET AND FUZZY LOGIC}

Fuzzy set theory is suitable for systems that involve imprecise and vague information. The fuzzy set theory was first introduced by Zadeh in 1965 as a mathematical method for representing vagueness in everyday life (14). It has been recognized as a useful mathematical tool in a variety of research fields, including transportation engineering and planning $(15,16,17,18)$.

Based on basic fuzzy set theory, Zadeh (19) first introduced fuzzy logic in 1973. Fuzzy logic is a mathematical representation of human concept formulation and reasoning. In recent years, fuzzy logic has been applied to practical problems with controls and decisions which involve or are similar to the imprecise human reasoning process. It is a promising mathematical approach for modeling traffic control processes which are characterized by subjectivity, ambiguity and imprecision (20). 


\section{Fuzzy Set}

In the classic theory of sets, also known as crisp set theory, very precise bounds separate the elements that belong to a certain set from the elements outside the set. In other words, it is easy to determine whether an element belongs to a set or not. The membership of element $x$ in set A is described in the classic theory of sets by the membership function $\mu_{A}(x)$, as follows:

$$
\mu_{A}(x)=\left\{\begin{array}{l}
1, \quad \text { if and only if } x \text { is a member of } A \\
0, \quad \text { if and only if } x \text { is not a member of } A
\end{array}\right.
$$

However, many sets encountered in real life do not have precisely defined bounds that separate the elements in the set from those outside the set. For example, if we denote by A the set of "long delay at a signal," how could we establish which element belongs to this set? Does a delay of $40 \mathrm{sec}$. belong to this set? What about $30 \mathrm{sec}$. or $60 \mathrm{sec}$.? It is obvious that the binary logic of having each single element to either belong to a set (membership $=1$ ) or not belong to a set (membership $=0$ ) is not appropriate for most categories describing real-world situations that do not possess well-defined boundaries. Fundamentally then this initiates the development of fuzzy set theory.

In contrast to the classical set theory, fuzzy sets admit intermediate values of class membership. A fuzzy set is represented by a membership function which expresses the degree that an element of the universal set belongs to the fuzzy set: larger values denote higher degrees of membership, smaller values indicate lower degrees of membership. The most commonly used range of values of membership functions is the unit interval $[0,1]$. Each membership function maps elements of a given universal set $X$ into real numbers in $[0,1]$. In other words, the membership function of a fuzzy set $A, \mu_{A}(x)$, is defined as

$$
\mu_{A}: X \rightarrow[0,1]
$$

\section{Fuzzy Logic}

The development of fuzzy logic dates back to 1973 (19). Introducing a concept he called “approximate reasoning”, Zadeh successfully showed that vague logical statements enable the formation of algorithms that can use vague data to derive vague inferences. Fuzzy logic makes it possible to compute with words, which enables complex analysis reflecting the human thinking process. Each fuzzy logic system can be divided into three elements (Figure 1): fuzzification, fuzzy inference and defuzzification $(15,21,22,23)$.

Input data are most often crisp values. Fuzzification maps crisp numbers into fuzzy sets. The fuzzifier decides the corresponding membership grades (or degrees of membership) from the crisp inputs. The resulting fuzzy values are then entered into the fuzzy inference engine. Fuzzy inference is based on a fuzzy rule base which contains a set of If $\rightarrow$ Then fuzzy rules. A typical fuzzy rule would be: 
If Queue Length is Long\} and \{Arriving Rate is High\} and \{Queue Length on the cross street is Short\}

Then $\quad$ Green Light is Extended\}

The fact following "If" is a premise or antecedent and the fact following "Then" is a consequent.

A fuzzy inference system can be composed of more than one rule with each rule consisting of more than one premise variable. The general form of fuzzy inference is as follows:

Input: $x_{1}=A$ and $x_{2}=B$ and $x_{3}=C$

Rule 1: If $x_{1}=A_{1}$ and $x_{2}=B_{1}$ and $x_{3}=C_{1}$ Then $y=D_{1}$

Rule $i$ : If $x_{1}=A_{i}$ and $x_{2}=B_{i}$ and $x_{3}=C_{i}$ Then $y=D_{i}$

............

$\underline{\text { Rule } n \text { :If } x_{1}=A_{n} \text { and } x_{2}=B_{n} \text { and } x_{3}=C_{n} \text { Then } y=D_{n}}$

Conclusion: $y=D^{\prime}$

where $A, B$, and $C$ are the values of input (either exact or approximate);

$A_{i}, B_{i}, C_{i}, D_{i}(i=1, \cdots, n)$ are conditions of $x_{1}, x_{2}, x_{3}$, and $y$ in the rule and are expressed in approximate terms using natural language.

During defuzzification, one value is chosen for the output variable. A commonly used defuzzification strategy for continuous membership functions is the centroid method (center of area) (15).

\section{METHODOLOGY}

Signal control is basically a process for allocating green time among conflicting movements. Alternatively, signal control is a process for determining whether or to extend or terminate the current green phase. The proposed fuzzy logic controller (FLC) works in the same way but it is significantly different from actuated control. Actuated control extends green time based on an extension interval, a maximum green time and the vehicular actuations on the subject approach. No examination of the conditions on conflicting movements and no optimization is involved in the actuated control process.

The proposed fuzzy logic controller determines whether to extend or terminate the current green phase based on a set of fuzzy rules. The fuzzy rules compare traffic conditions with the current green phase and traffic conditions with the next candidate green phase. The set of control parameters is:

QC = Average queue length on the lanes served by the current green, in veh/lane.

QN = Average queue length on lanes with red which may receive green in the next phase, in veh/lane.

$\mathbf{A R}=$ Average arrival rate on lanes with the current green, in veh/sec/lane 
$\mathbf{T}_{\text {MIN }}=$ minimum green time for each phase, in sec.

$\mathbf{T}_{\mathbf{M A X} \mathbf{T}_{-} \mathbf{T H}}=$ maximum green time for through lanes which can vary for different approaches, in sec.

$\mathbf{T}_{\text {MAX_LT }}=$ maximum green time for left-turn lanes which can vary for different approaches, in sec.

The fuzzy logic controller determines whether to extend or terminate the current green phase after a minimum green time of $\mathrm{T}_{\mathrm{MIN}}$ has been displayed. If the green time is extended, then the fuzzy logic controller will determine whether to extend the green after a time interval $\Delta t$. The interval $\Delta t$ may vary from 0.1 to $10 \mathrm{sec}$. depending on the controller processor speed. $\Delta \mathrm{t}=5 \mathrm{sec}$. in this study. If the fuzzy logic controller determines to terminate the current phase, then the signal will go to the next phase. If not, the current phase will be extended and the fuzzy logic controller will make the next decision after $\Delta \mathrm{t}$ and so forth until the maximum green time is reached.

The decision making process is based on a set of fuzzy rules which takes into account the traffic conditions with the current and next phases. The general format of the fuzzy rules is as follows:

If $\left\{\mathrm{QC}\right.$ is $\left.\mathrm{X}_{1}\right\}$ and $\left\{\mathrm{AR}\right.$ is $\left.\mathrm{X}_{2}\right\}$ and $\left\{\mathrm{QN}\right.$ is $\left.\mathrm{X}_{3}\right\}$ Then $\{\mathrm{E}$ or $\mathrm{T}\}$.

where,

$\mathrm{X}_{1}, \mathrm{X}_{2}, \mathrm{X}_{3}=$ natural language expressions of traffic conditions of respective variables

$\mathrm{E}=$ Extension of green phase

$\mathrm{T}=$ Termination of green phase

QC and QN are divided into four fuzzy sets: “short,” “medium,” "long” and "very long.” AR is divided into three fuzzy sets: “low," "medium” and "high.” The number of fuzzy rules is dependent on the combinations of fuzzy sets for $X_{1}, X_{2}$, and $X_{3}$. A total of $4 \times 3 \times 4=48$ fuzzy rules are listed in Table 1 .

The parameters QC, QN, and AR are characterized by fuzzy numbers as shown in Figure 2. Trapezoidal fuzzy numbers are used in this study. $\mathrm{Q}_{1}$ to $\mathrm{Q}_{6}$ are threshold values to define fuzzy sets for $\mathrm{QC}$ and $\mathrm{QN} ; \mathrm{AR}_{1}$ to $\mathrm{AR}_{4}$ are threshold values to define fuzzy sets for $\mathrm{AR}$.

The input data (traffic conditions) are first fuzzified using the proposed fuzzy sets for QC, QN, and AR. Then the fuzzified input data are entered into the fuzzy inference system which is composed of a set of fuzzy rules as described above. The max-min composition method $(15,17,23)$ is applied for making inferences. The membership grades (or degrees of membership, between 0 and 1) for $\mathrm{E}$ (Extend) and $\mathrm{T}$ (Terminate) are compared. The one with the highest membership grade is chosen as the control action.

The initial threshold values for fuzzy sets for QC, QN, and AR are shown in Figure 3.

The entire fuzzy logic control process can be represented with a simple example as follows. Suppose that after a time interval $\Delta \mathrm{t}=5 \mathrm{sec}$. (within the maximum green time), the fuzzy logic controller 
needs to make a decision whether to extend or terminate the current green phase based on the following traffic conditions:

$$
\begin{aligned}
& \mathrm{QC}=7.5 \mathrm{veh} / \mathrm{lane} \\
& \mathrm{AR}=0.18 \mathrm{veh} / \mathrm{sec} / \mathrm{lane} \\
& \mathrm{QN}=10.5 \mathrm{veh} / \mathrm{lane}
\end{aligned}
$$

Based on Figure 3, the input data QC, AR, and QN are fuzzified as shown in Table 2. Based on the fuzzified input data, it is found that fuzzy rules 19, 20, 23, 24, 31, 32, 35, and 36 in Table 1 are involved in this fuzzy inference. The fuzzy inference procedure using max-min composition method is shown in Table 3. Based on the fuzzy logic inference procedure, the fuzzy logic controller will decide to extend the green time for the current phase.

\section{SIMULATION TOOL}

A new intersection simulation software, Intersection Control Simulator (ICS), was developed based on the intersection simulator NIT $(3,24)$. NIT was originally developed to evaluate a new adaptive control strategy TACOS $(3,4)$. ICS is a microscopic, stochastic, interval-oriented traffic simulator programmed in $\mathrm{C}++$. ICS emulates NETSIM and Integration and was designed to be able to simulate the intersection operation under pretimed, actuated, and FLC control.

ICS scans the traffic system and summarizes measures of effectiveness (MOE) at each time interval. MOE for each lane are necessary to evaluate the performance of different signal control strategies. Link-based, approach-based and intersection-wide MOE can be derived from lane-based MOE using weighted aggregation. The lane-based MOE estimators of ICS include a throughput estimator, a speed estimator, a delay estimator and a queue estimator. A comprehensive test showed that ICS is a valid tool for testing various intersection control strategies $(3,4,24)$.

\section{CASE STUDY}

FLC was evaluated against pretimed and actuated control strategies. The MOE used in the evaluation were (1) network delay, (2) network speed, (3) \% stops, (4) network time in queue, and (5) network throughput-to-demand ratio. The best control strategy is the one that provides the lowest delay, highest speed, lowest \% stops, lowest time in queue, and highest throughput-to-demand ratio.

The geometry of the intersection is illustrated in Figure 4(a). Left-turn lanes were made long enough to accommodate left-turning traffic queues. Traffic volumes varying from $20 \%$ to $100 \%$ of the highest volume are shown in Figure 4(b). The 100\% traffic volume level represents a condition where two conflicting movements have a volume-to-capacity ratio greater than 1.0, thus, the intersection is substantially over-saturated 
Two simplifications were applied: no right turn on red and no pedestrian demand. The pretimed signal timings shown in Figure 4(c) were optimized with TRANSYT-7F using “delay and stops" as the objective function. Figure 4(d) displays the actuated control phases and phase timing. Vehicle extension intervals of 2, 3 and 4 sec. were tried and the value that produced the best performance in terms of speed and delay was used to compare actuated control with FLC. The phase flags for the actuated signal timing were set as: Vehicle Recall $=$ ON, Double Entry $=$ ON, Simultaneous Gapout $=$ ON, Lag $=$ ON, all the

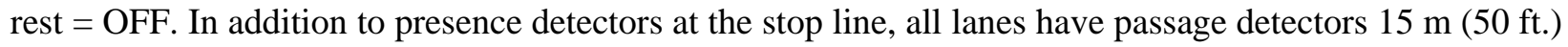
upstream the stop line. These detectors place calls when the phase is active.

Five different combinations of control parameters $\left(\mathrm{Q}_{1}-\mathrm{Q}_{6}, \mathrm{AR}_{1}-\mathrm{AR}_{4}, \mathrm{~T}_{\mathrm{MAX} \_ \text {TH }}, \mathrm{T}_{\mathrm{MAX} \_\mathrm{LT}}\right.$, and $\left.\mathrm{T}_{\mathrm{MIN}}\right)$ were tried for FLC control and the best one in terms of delay, speed, \% stops, and time in queue was chosen for the comparison among FLC, pretimed and actuated control strategies. Because of the stochastic nature of simulation models, each simulation run may produce different results. For this study, 20 simulation runs were performed for each scenario, resulting in a total of $(5+2) \times 5 \times 20=700$ simulation runs. The average values of delay, speed, \% stops, time in queue, and throughput-to demand ratio from the 20 simulation runs were averaged to obtain the final MOE for each scenario. Each simulation run was based on a 30-minute simulation time.

The simulation results for FLC are listed in the lower half of Table 4. The columns with shaded background are the best FLC control for each volume level. As expected, FLC control parameters increase with increasing traffic volumes.

FLC is compared with pretimed and actuated control as summarized in Figure 5. The summary table in Figure 5(a) shows average proportional differences of FLC's MOE over pretimed and actuated control for the test intersection. FLC produced the best performance for all MOE examined.

Further inspection of the delay, speed, \% stops, time in queue, and throughput-to-demand ratio (Figure 5) show that:

- Delay: FLC produced the lowest delay at the $60 \%, 80 \%$, and $100 \%$ volume levels. The improvements are more significant with increasing traffic volume. FLC produced a lower delay than pretimed control but a higher delay than actuated control at the $40 \%$ volume level. Both pretimed and actuated controls produced lower delay than FLC at the 20\% volume level.

- Speed: FLC produced the highest speed at the $60 \%, 80 \%$ and $100 \%$ volume levels. FLC produced a higher speed than pretimed control but a lower speed than actuated control at the $40 \%$ volume level. Both pretimed and actuated controls produced a higher speed than FLC at the $20 \%$ volume level. 
- \% stops: FLC produced a lower \% stops than pretimed control at all levels of traffic volume. FLC also produced a lower \% stops than actuated control at the $20 \%, 40 \%$, and $60 \%$ volume levels. However, actuated control performed better than FLC at the $80 \%$ and $100 \%$ volume levels.

- $\quad$ Time in Queue: FLC produced the lowest time in queue at the $60 \%, 80 \%$ and $100 \%$ volume levels. FLC produced a shorter time in queue than pretimed control but a longer time in queue than actuated control at the $40 \%$ volume level. Both pretimed and actuated controls produced shorter times in queue than FLC at the 20\% volume level.

- Throughput-to-demand ratio: FLC consistently produced higher throughput-to-demand ratios than pretimed and actuated control at all volume levels. The improvement is more pronounced at higher levels of traffic volume.

Overall, the FLC strategy produced substantial improvements over the pretimed and actuated control strategies under heavy traffic conditions in terms of delay, speed, time in queue and throughput.

The FLC parameters in all five trials for heavily loaded volume levels (80\% and $100 \%)$ produced superior delay, speed, time in queue and throughput estimates compared with pretimed and actuated control estimates (Table 4). This indicates that parameters for running the FLC can be selected with ease for intersections with heavy traffic volumes.

\section{CONCLUSION}

A basic fuzzy logic control (FLC) algorithm for full intersections with two-way streets and leftturn lanes was developed. The FLC strategy simulates the control logic of experienced humans such as police officers directing traffic who often replace signal controls when intersections experience unusually heavy traffic volumes (e.g., during special events.) The FLC controller makes the decision whether to extend or terminate the current green phase based on a set of fuzzy rules and real-time traffic information.

The microscopic intersection control simulator (ICS) facilitated the evaluation of the proposed FLC strategy. FLC was compared with pretimed and actuated control strategies using a typical intersection with varying traffic volume levels. Measures of effectiveness including delay, speed, \% stops, time in queue, and throughput-to-demand ratio were examined. FLC showed substantial improvements over pretimed and actuated control strategies for all MOE except \% stops under heavy traffic volumes. Overall, the simulation results indicated that FLC has the potential to improve operations at oversaturated intersections. The parameters required for running FLC can be set easily for intersections with heavy traffic. 
The application of this control strategy depends on queue length estimation. This can be accomplished by algorithms using upstream arrivals and stopline departures, or by using midblock loops, or by using unintrusive sensors including image based sensors.

A large number of improvements are planned for the future; they include the following:

- Additional simulation tests on intersections with different levels of geometric complexity, phasing and demand.

- One of the reviewers noted that similar to common traffic-actuate control the proposed FLC also uses a maximum green, therefore the FLC may also default to a suboptimal pretimed operation at over-saturated conditions. So far, simulations indicate that the maximum green time has a limited role in the control. However, enrichment of the fuzzy rules is planned so that maximum green times could be eventually avoided.

- The time interval $\Delta \mathrm{t}$ may be tested with shorter steps to further increase signal efficiency considering the fast processing speed of current controllers.

- Laboratory comparisons with other adaptive control strategies such as OPAC, RHODES and RTACL are important. These control strategies along with the FLC described herein are planned to be evaluated using VISSIM's VAP module (25) that allows for the development of userdefined signal logic. The use of well-known software such as VISSIM will facilitate independent comparisons among different control strategies.

- Expansion of the FLC strategy to arterial and network applications.

\section{REFERENCES}

1. Meyer, M. D. A Toolbox for Alleviating Traffic Congestion and Enhancing Mobility. ITE, 1997.

2. Tarnoff, P. J., and P. S. Parsonson. Selecting Traffic Signal Control at Individual Intersections. NCHRP Report 233, TRB, National Research Council, Washington, D.C., 1981.

3. Li, H. Traffic Adaptive Control for Isolated, Over-saturated Intersections. Ph.D. Dissertation, Department of Civil Engineering, University of Hawaii at Manoa, Honolulu, Hawaii, 2002.

4. Li, H., and P. D. Prevedouros. Traffic Adaptive Control Integrated with Phase Optimization: Model Development and Simulation Testing. In Journal of Transportation Engineering, ASCE, Vol. 30, No. 5, September 2004, pp. 594-601.

5. Pappis, C. P., and E. H. Mamdani. A Fuzzy Logic Controller for a Traffic Junction. IEEE Transactions on Systems, Man, and Cybernetics, Vol. SMC-7, No. 10, October 1977, pp. 707-717.

6. Kelsey, R. L., and K. R. Bisset. Simulation of Traffic Flow and Control Using Fuzzy and Conventional Methods. Fuzzy Logic and Control: Software and Hardware Applications, Prentice Hall, Englewood Cliffs, New Jersey, 1993, pp. 262-278. 
7. Niittymaki, J., and M. Pursula. Signal Control Using Fuzzy Logic. Fuzzy Sets and Systems, Vol. 116, 2000, pp. 11-22.

8. Trabia, M. B., M. S. Kaseko, and M. Ande. A Two-Stage Fuzzy Logic Controller for Traffic Signals. Transportation Research, Part C, Vol. 7, 1999, pp. 353-367.

9. Niittymaki, J., and S. Kikuchi. Application of Fuzzy Logic to the Control of a Pedestrian Crossing Signal. In Transportation Research Record: Journal of the Transportation Research Board, No. 1651, TRB, National Research Council, Washington, D.C., 1998, pp. 30-38.

10. Chen, L. L., A. D. May, and D. M. Auslander. Freeway Ramp Control Using Fuzzy Set Theory for Inexact Reasoning. Transportation Research, Part A, Vol. 24, No. 1, 1990, pp. 15-25.

11. Nakatsuyama, M., H. Nagahashi, and N. Nishizuka. Fuzzy Logic Phase Controller for Traffic Junctions in the One-Way Arterial Road. Proceedings of the IFAC Ninth Triennial World Congress, 1984, pp. 2865-2870.

12. Chiu, S. Adaptive Traffic Signal Control Using Fuzzy Logic. Proceedings of the IEEE Intelligent Vehicles Symposium, 1992, pp. 98-107.

13. Niittymaki, J. Installation and Experiences of Field Testing a Fuzzy Signal Controller. European Journal of Operation Research, Vol. 131, 2001, pp. 273-281.

14. Zadeh, L. A. Fuzzy Sets. Information and Control, Vol.8, 1965, pp.338-353.

15. Klir, G. J., and B. Yuan. Fuzzy Sets and Fuzzy Logic: Theory and Applications. Prentice Hall, Englewood Cliffs, New Jersey, 1995.

16. Klir, G. J., and T. A. Folger. Fuzzy Sets, Uncertainty, and Information. Prentice Hall, Englewood Cliffs, New Jersey, 1988.

17. Teodorovic, D., and K. Vukadinovic. Traffic Control and Transport Planning: A Fuzzy Sets and Neural Networks Approach. Kluwer Academic Publishers, Boston/Dordrecht/London, 1998.

18. Dubois, D., and H. Prade. Fuzzy Sets and Systems: Theory and Applications. Academic Press, New York, 1980.

19. Zadeh, L.A. Outline of a New Approach to the Analysis of Complex Systems and Decision Processes. IEEE Transactions on Systems, Man, and Cybernetics, Vol. SMC-3, No. 1, 1973, pp. 28-44.

20. Teodorovic, D. Fuzzy Logic Systems for Transportation Engineering: the State of the Art. Transportation Research, Part A, Vol. 33, 1999, pp. 337-364.

21. Chang, E. C.., and S. H. Wang. Improved Freeway Incident Detection Using Fuzzy Set Theory. In Transportation Research Record: Journal of the Transportation Research Board, No. 1453, TRB, National Research Council, Washington, D.C., 1994, pp. 75-82. 
22. Kikuchi, S., and D. Miljkovic. Use of Fuzzy Inference for Modeling Prediction of Transit Ridership at Individual Stops. In Transportation Research Record: Journal of the Transportation Research Board, No. 1774, TRB, National Research Council, Washington, D.C., 2001, pp. 25-35.

23. Pedrycz, W., and F. Gomide. An Introduction to Fuzzy Sets: Analysis and Design. The MIT Press, Cambridge, Massachusetts, 1998.

24. Li, H., P. D. Prevedouros, and L. Zhang. Development and Testing of the NETSIM, INTEGRATION and TACOS Simulator, NIT. Paper 04-3221, 83 ${ }^{\text {rd }}$ Annual Meeting of TRB, National Research Council, Washington D.C., January 2004.

25. VISSIM User Manual, Version 4.00. PTV AG, Germany, 2004. 


\section{List of Tables}

TABLE 1. Fuzzy Rules

TABLE 2. Fuzzification of Input Traffic Data

TABLE 3. Fuzzy Inference using Max-Min Composition Method

TABLE 4. Parameters for Fuzzy Logic Controller

\section{List of Figures}

FIGURE 1. Fuzzy logic system.

FIGURE 2. Fuzzy sets for QC, QN and AR.

FIGURE 3. Initial threshold values for fuzzy sets for QC, QN and AR.

FIGURE 4. Basics of signalized intersection used in case study.

FIGURE 5. Results of case study. 


\section{TABLE 1. Fuzzy Rules}

\begin{tabular}{|c|c|}
\hline No. & Fuzzy Rules \\
\hline 1 & If $\{\mathrm{QC}$ is short $\}$ and $\{\mathrm{AR}$ is low $\}$ and $\{\mathrm{QN}$ is short $\}$, Then $\{\mathrm{E}\}$. \\
\hline 2 & If $\{\mathrm{QC}$ is short $\}$ and $\{\mathrm{AR}$ is low $\}$ and $\{\mathrm{QN}$ is medium $\}$, Then $\{\mathrm{T}\}$. \\
\hline 3 & If $\{\mathrm{QC}$ is short $\}$ and $\{\mathrm{AR}$ is low $\}$ and $\{\mathrm{QN}$ is long $\}$, Then $\{\mathrm{T}\}$. \\
\hline 4 & If $\{\mathrm{QC}$ is short $\}$ and $\{\mathrm{AR}$ is low $\}$ and $\{\mathrm{QN}$ is very long $\}$, Then $\{\mathrm{T}\}$. \\
\hline 5 & If $\{\mathrm{QC}$ is short $\}$ and $\{\mathrm{AR}$ is medium $\}$ and $\{\mathrm{QN}$ is short $\}$, Then $\{\mathrm{E}\}$. \\
\hline 6 & If $\{\mathrm{QC}$ is short $\}$ and $\{\mathrm{AR}$ is medium $\}$ and $\{\mathrm{QN}$ is medium $\}$, Then $\{\mathrm{T}\}$. \\
\hline 7 & If $\{\mathrm{QC}$ is short $\}$ and $\{\mathrm{AR}$ is medium $\}$ and $\{\mathrm{QN}$ is long $\}$, Then $\{\mathrm{T}\}$. \\
\hline 8 & If $\{\mathrm{QC}$ is short $\}$ and $\{\mathrm{AR}$ is medium $\}$ and $\{\mathrm{QN}$ is very long $\}$, Then $\{\mathrm{T}\}$. \\
\hline 9 & If $\{\mathrm{QC}$ is short $\}$ and $\{\mathrm{AR}$ is high $\}$ and $\{\mathrm{QN}$ is short $\}$, Then $\{\mathrm{E}\}$. \\
\hline 10 & If $\{\mathrm{QC}$ is short $\}$ and $\{\mathrm{AR}$ is high $\}$ and $\{\mathrm{QN}$ is medium $\}$, Then $\{\mathrm{E}\}$. \\
\hline 11 & If $\{\mathrm{QC}$ is short $\}$ and $\{\mathrm{AR}$ is high $\}$ and $\{\mathrm{QN}$ is long $\}$, Then $\{\mathrm{T}\}$. \\
\hline 12 & If $\{\mathrm{QC}$ is short $\}$ and $\{\mathrm{AR}$ is high $\}$ and $\{\mathrm{QN}$ is very long $\}$, Then $\{\mathrm{T}\}$. \\
\hline 13 & If $\{\mathrm{QC}$ is medium $\}$ and $\{\mathrm{AR}$ is low $\}$ and $\{\mathrm{QN}$ is short $\}$, Then $\{\mathrm{E}\}$. \\
\hline 14 & If $\{\mathrm{QC}$ is medium $\}$ and $\{\mathrm{AR}$ is low $\}$ and $\{\mathrm{QN}$ is medium $\}$, Then $\{\mathrm{E}\}$. \\
\hline 15 & If $\{\mathrm{QC}$ is medium $\}$ and $\{\mathrm{AR}$ is low $\}$ and $\{\mathrm{QN}$ is long $\}$, Then $\{\mathrm{T}\}$. \\
\hline 16 & If $\{\mathrm{QC}$ is medium $\}$ and $\{\mathrm{AR}$ is low $\}$ and $\{\mathrm{QN}$ is very long $\}$, Then $\{\mathrm{T}\}$. \\
\hline 17 & If $\{\mathrm{QC}$ is medium $\}$ and $\{\mathrm{AR}$ is medium $\}$ and $\{\mathrm{QN}$ is short $\}$, Then $\{\mathrm{E}\}$. \\
\hline 18 & If $\{\mathrm{QC}$ is medium $\}$ and $\{\mathrm{AR}$ is medium $\}$ and $\{\mathrm{QN}$ is medium $\}$, Then $\{\mathrm{E}\}$. \\
\hline 19 & If $\{\mathrm{QC}$ is medium $\}$ and $\{\mathrm{AR}$ is medium $\}$ and $\{\mathrm{QN}$ is long $\}$, Then $\{\mathrm{T}\}$. \\
\hline 20 & If $\{\mathrm{QC}$ is medium $\}$ and $\{\mathrm{AR}$ is medium $\}$ and $\{\mathrm{QN}$ is very long $\}$, Then $\{\mathrm{T}\}$. \\
\hline 21 & If $\{\mathrm{QC}$ is medium $\}$ and $\{\mathrm{AR}$ is high $\}$ and $\{\mathrm{QN}$ is short $\}$, Then $\{\mathrm{E}\}$. \\
\hline 22 & If $\{\mathrm{QC}$ is medium $\}$ and $\{\mathrm{AR}$ is high $\}$ and $\{\mathrm{QN}$ is medium $\}$, Then $\{\mathrm{E}\}$. \\
\hline 23 & If $\{\mathrm{QC}$ is medium $\}$ and $\{\mathrm{AR}$ is high $\}$ and $\{\mathrm{QN}$ is long $\}$, Then $\{\mathrm{E}\}$. \\
\hline 24 & If $\{\mathrm{QC}$ is medium $\}$ and $\{\mathrm{AR}$ is high $\}$ and $\{\mathrm{QN}$ is very long $\}$, Then $\{\mathrm{T}\}$. \\
\hline 25 & If $\{\mathrm{QC}$ is long $\}$ and $\{\mathrm{AR}$ is low $\}$ and $\{\mathrm{QN}$ is short $\}$, Then $\{\mathrm{E}\}$. \\
\hline 26 & If $\{\mathrm{QC}$ is long $\}$ and $\{\mathrm{AR}$ is low $\}$ and $\{\mathrm{QN}$ is medium $\}$, Then $\{\mathrm{E}\}$. \\
\hline 27 & If $\{\mathrm{QC}$ is long $\}$ and $\{\mathrm{AR}$ is low $\}$ and $\{\mathrm{QN}$ is long $\}$, Then $\{\mathrm{E}\}$. \\
\hline 28 & If $\{\mathrm{QC}$ is long $\}$ and $\{\mathrm{AR}$ is low $\}$ and $\{\mathrm{QN}$ is very long $\}$, Then $\{\mathrm{T}\}$. \\
\hline 29 & If $\{\mathrm{QC}$ is long $\}$ and $\{\mathrm{AR}$ is medium $\}$ and $\{\mathrm{QN}$ is short $\}$, Then $\{\mathrm{E}\}$. \\
\hline 30 & If $\{\mathrm{QC}$ is long $\}$ and $\{\mathrm{AR}$ is medium $\}$ and $\{\mathrm{QN}$ is medium $\}$, Then $\{\mathrm{E}\}$. \\
\hline 31 & If $\{\mathrm{QC}$ is long $\}$ and $\{\mathrm{AR}$ is medium $\}$ and $\{\mathrm{QN}$ is long $\}$, Then $\{\mathrm{E}\}$. \\
\hline 32 & If $\{\mathrm{QC}$ is long $\}$ and $\{\mathrm{AR}$ is medium $\}$ and $\{\mathrm{QN}$ is very long $\}$, Then $\{\mathrm{T}\}$. \\
\hline 33 & If $\{\mathrm{QC}$ is long $\}$ and $\{\mathrm{AR}$ is high $\}$ and $\{\mathrm{QN}$ is short $\}$, Then $\{\mathrm{E}\}$. \\
\hline 34 & If $\{\mathrm{QC}$ is long $\}$ and $\{\mathrm{AR}$ is high $\}$ and $\{\mathrm{QN}$ is medium $\}$, Then $\{\mathrm{E}\}$. \\
\hline 35 & If $\{\mathrm{QC}$ is long $\}$ and $\{\mathrm{AR}$ is high $\}$ and $\{\mathrm{QN}$ is long $\}$, Then $\{\mathrm{E}\}$. \\
\hline 36 & If $\{\mathrm{QC}$ is long $\}$ and $\{\mathrm{AR}$ is high $\}$ and $\{\mathrm{QN}$ is very long $\}$, Then $\{\mathrm{E}\}$. \\
\hline 37 & If $\{Q C$ is very long $\}$ and $\{A R$ is low $\}$ and $\{Q N$ is short $\}$, Then $\{E\}$. \\
\hline 38 & If $\{\mathrm{QC}$ is very long $\}$ and $\{\mathrm{AR}$ is low $\}$ and $\{\mathrm{QN}$ is medium $\}$, Then $\{\mathrm{E}\}$. \\
\hline 39 & If $\{\mathrm{QC}$ is very long $\}$ and $\{\mathrm{AR}$ is low $\}$ and $\{\mathrm{QN}$ is long $\}$, Then $\{\mathrm{E}\}$. \\
\hline 40 & If $\{Q C$ is very long $\}$ and $\{A R$ is low $\}$ and $\{Q N$ is very long $\}$, Then $\{E\}$. \\
\hline 41 & If $\{\mathrm{QC}$ is very long $\}$ and $\{\mathrm{AR}$ is medium $\}$ and $\{\mathrm{QN}$ is short $\}$, Then $\{\mathrm{E}\}$. \\
\hline 42 & If $\{\mathrm{QC}$ is very long $\}$ and $\{\mathrm{AR}$ is medium $\}$ and $\{\mathrm{QN}$ is medium $\}$, Then $\{\mathrm{E}\}$. \\
\hline 43 & If $\{\mathrm{QC}$ is very long $\}$ and $\{\mathrm{AR}$ is medium $\}$ and $\{\mathrm{QN}$ is long $\}$, Then $\{\mathrm{E}\}$. \\
\hline 44 & If $\{\mathrm{QC}$ is very long $\}$ and $\{\mathrm{AR}$ is medium $\}$ and $\{\mathrm{QN}$ is very long $\}$, Then $\{\mathrm{E}\}$. \\
\hline 45 & If $\{\mathrm{QC}$ is very long $\}$ and $\{\mathrm{AR}$ is high $\}$ and $\{\mathrm{QN}$ is short $\}$, Then $\{\mathrm{E}\}$. \\
\hline 46 & If $\{\mathrm{QC}$ is very long $\}$ and $\{\mathrm{AR}$ is high $\}$ and $\{\mathrm{QN}$ is medium $\}$, Then $\{\mathrm{E}\}$. \\
\hline 47 & If $\{\mathrm{QC}$ is very long $\}$ and $\{\mathrm{AR}$ is high $\}$ and $\{\mathrm{QN}$ is long $\}$, Then $\{\mathrm{E}\}$. \\
\hline 48 & If $\{\mathrm{QC}$ is very long $\}$ and $\{\mathrm{AR}$ is high $\}$ and $\{\mathrm{QN}$ is very long $\}$, Then $\{\mathrm{E}\}$. \\
\hline
\end{tabular}

E: Extend; T: Terminate 
TABLE 2. Fuzzification of Input Traffic Data

\begin{tabular}{|c|c|c|c|}
\hline Input & Traffic Data & Fuzzified Category & Membership Grade \\
\hline \multirow{2}{*}{ QC } & \multirow{2}{*}{7.5 veh/lane } & Medium & 0.25 \\
\hline & & Long & 0.75 \\
\hline \multirow{2}{*}{ AR } & \multirow{2}{*}{$0.18 \mathrm{veh} / \mathrm{sec} /$ lane } & Medium & 0.70 \\
\hline & & High & 0.30 \\
\hline \multirow{2}{*}{ QN } & \multirow{2}{*}{10.5 veh/lane } & Long & 0.75 \\
\hline & & Very long & 0.25 \\
\hline
\end{tabular}


TABLE 3. Fuzzy Inference using Max-Min Composition Method

\begin{tabular}{|c|c|c|c|c|}
\hline \multicolumn{3}{|c|}{ Traffic Information } & \multirow{2}{*}{$\begin{array}{l}\text { Control } \\
\text { Action }\end{array}$} & \multirow{2}{*}{ Max-Min Composition } \\
\hline QC & AR & QN & & \\
\hline $\begin{array}{c}\text { Medium } \\
(0.25)\end{array}$ & $\begin{array}{c}\text { Medium } \\
(0.70)\end{array}$ & $\begin{array}{l}\text { Long } \\
(0.75)\end{array}$ & $\mathrm{T}$ & $\operatorname{Min}(0.25,0.70,0.75)=0.25$ \\
\hline $\begin{array}{l}\text { Medium } \\
(0.25)\end{array}$ & $\begin{array}{c}\text { Medium } \\
(0.70)\end{array}$ & $\begin{array}{c}\text { Very long } \\
(0.25)\end{array}$ & $\mathrm{T}$ & $\operatorname{Min}(0.25,0.70,0.25)=0.25$ \\
\hline $\begin{array}{c}\text { Medium } \\
(0.25)\end{array}$ & $\begin{array}{c}\text { High } \\
(0.30)\end{array}$ & $\begin{array}{c}\text { Long } \\
(0.75)\end{array}$ & $\mathrm{E}$ & $\operatorname{Min}(0.25,0.30,0.75)=0.25$ \\
\hline $\begin{array}{c}\text { Medium } \\
(0.25)\end{array}$ & $\begin{array}{c}\text { High } \\
(0.30)\end{array}$ & $\begin{array}{c}\text { Very long } \\
(0.25)\end{array}$ & $\mathrm{T}$ & $\operatorname{Min}(0.25,0.30,0.25)=0.25$ \\
\hline $\begin{array}{c}\text { Long } \\
(0.75) \\
\end{array}$ & $\begin{array}{c}\text { Medium } \\
(0.70)\end{array}$ & $\begin{array}{c}\text { Long } \\
(0.75) \\
\end{array}$ & $\mathrm{E}$ & $\operatorname{Min}(0.75,0.70,0.75)=0.70$ \\
\hline $\begin{array}{c}\text { Long } \\
(0.75)\end{array}$ & $\begin{array}{c}\text { Medium } \\
(0.70)\end{array}$ & $\begin{array}{c}\text { Very long } \\
(0.25)\end{array}$ & $\mathrm{T}$ & $\operatorname{Min}(0.75,0.70,0.25)=0.25$ \\
\hline $\begin{array}{l}\text { Long } \\
(0.75)\end{array}$ & $\begin{array}{c}\text { High } \\
(0.30)\end{array}$ & $\begin{array}{c}\text { Long } \\
(0.75)\end{array}$ & $\mathrm{E}$ & $\operatorname{Min}(0.75,0.30,0.75)=0.30$ \\
\hline \multirow[t]{2}{*}{$\begin{array}{l}\text { Long } \\
(0.75)\end{array}$} & $\begin{array}{l}\text { High } \\
(0.30)\end{array}$ & $\begin{array}{c}\text { Very long } \\
(0.25)\end{array}$ & $\mathrm{E}$ & $\operatorname{Min}(0.75,0.30,0.25)=0.25$ \\
\hline & & & \multicolumn{2}{|c|}{$\begin{array}{l}\text { T: } \operatorname{Max}(0.25,0.25,0.25,0.25)=0.25 \\
\text { E: Max }(0.25,0.70,0.30,0.25)=0.70 \\
0.70>0.25 \rightarrow \\
\text { Final decision: EXTENSION }\end{array}$} \\
\hline
\end{tabular}

E: Extend; T: Terminate

The number in parenthesis "()" is the corresponding membership grade. 
TABLE 4. Parameters for Fuzzy Logic Controller

\begin{tabular}{|c|c|c|c|c|c|c|c|c|c|c|c|c|c|c|c|c|c|c|c|c|c|c|c|c|c|c|}
\hline & \multirow[b]{3}{*}{ Trials } & \multicolumn{25}{|c|}{ Volume Level } \\
\hline & & \multicolumn{5}{|c|}{$20 \%$} & \multicolumn{5}{|c|}{$40 \%$} & \multicolumn{5}{|c|}{$60 \%$} & \multicolumn{5}{|c|}{$80 \%$} & \multicolumn{5}{|c|}{$100 \%$} \\
\hline & & 1 & 2 & 3 & 4 & 5 & 1 & 2 & 3 & 4 & 5 & 1 & 2 & 3 & 4 & 5 & 1 & 2 & 3 & 4 & 5 & 1 & 2 & 3 & 4 & 5 \\
\hline \multirow{13}{*}{ 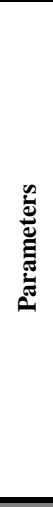 } & $\mathrm{Q}_{1}$ & 1 & 1 & 1 & 0.5 & 0.5 & 2 & 2 & 1 & 1 & 1 & 2 & 2 & 2 & 1 & 1 & 2 & 3 & 2 & 2 & 2 & 2 & 3 & 3 & 3 & 3 \\
\hline & $\mathrm{Q}_{2}$ & 2 & 2 & 2 & 1 & 1 & 4 & 4 & 2 & 2 & 2 & 4 & 4 & 4 & 2 & 2 & 4 & 6 & 4 & 4 & 4 & 4 & 6 & 6 & 6 & 6 \\
\hline & $\mathrm{Q}_{3}$ & 3 & 3 & 3 & 1.5 & 1.5 & 6 & 6 & 3 & 3 & 3 & 6 & 6 & 6 & 4 & 4 & 6 & 9 & 6 & 6 & 6 & 6 & 9 & 9 & 9 & 9 \\
\hline & $\mathrm{Q}_{4}$ & 5 & 4 & 4 & 2 & 2 & 8 & 8 & 5 & 5 & 4 & 8 & 8 & 8 & 6 & 6 & 8 & 12 & 8 & 8 & 8 & 8 & 12 & 12 & 12 & 12 \\
\hline & $\mathrm{Q}_{5}$ & 7 & 5 & 5 & 2.5 & 2.5 & 10 & 10 & 7 & 7 & 5 & 10 & 10 & 10 & 8 & 8 & 10 & 15 & 10 & 10 & 10 & 10 & 15 & 15 & 15 & 15 \\
\hline & $\mathrm{Q}_{6}$ & 9 & 6 & 6 & 3 & 3 & 12 & 12 & 9 & 9 & 6 & 12 & 12 & 12 & 10 & 10 & 12 & 18 & 12 & 12 & 12 & 12 & 18 & 18 & 18 & 18 \\
\hline & $\mathrm{AR}_{1}$ & 0.05 & 0.04 & 0.04 & 0.04 & 0.03 & 0.05 & 0.05 & 0.05 & 0.04 & 0.04 & 0.05 & 0.05 & 0.05 & 0.05 & 0.05 & 0.05 & 0.05 & 0.05 & 0.05 & 0.05 & 0.05 & 0.05 & 0.05 & 0.05 & 0.05 \\
\hline & $\mathrm{AR}_{2}$ & 0.10 & 0.08 & 0.08 & 0.08 & 0.06 & 0.10 & 0.10 & 0.10 & 0.08 & 0.08 & 0.10 & 0.10 & 0.10 & 0.09 & 0.10 & 0.10 & 0.10 & 0.10 & 0.10 & 0.10 & 0.10 & 0.10 & 0.10 & 0.10 & 0.10 \\
\hline & $\mathrm{AR}_{3}$ & $\begin{array}{l}0.15 \\
\end{array}$ & $\begin{array}{l}0.12 \\
\end{array}$ & $\begin{array}{l}0.12 \\
\end{array}$ & $\begin{array}{l}0.12 \\
\end{array}$ & 0.09 & $\begin{array}{l}0.15 \\
\end{array}$ & 0.15 & $\begin{array}{l}0.15 \\
\end{array}$ & $\begin{array}{l}0.12 \\
\end{array}$ & 0.12 & $\begin{array}{l}0.15 \\
\end{array}$ & 0.15 & $\begin{array}{l}0.15 \\
\end{array}$ & 0.13 & 0.15 & $\begin{array}{l}0.15 \\
\end{array}$ & $\begin{array}{l}0.15 \\
\end{array}$ & 0.15 & 0.15 & 0.15 & $\begin{array}{l}0.15 \\
\end{array}$ & $\begin{array}{l}0.15 \\
\end{array}$ & 0.15 & $\begin{array}{l}0.15 \\
\end{array}$ & 0.20 \\
\hline & $\mathrm{AR}_{4}$ & 0.20 & 0.16 & 0.16 & 0.16 & 0.12 & 0.20 & 0.20 & 0.20 & 0.16 & 0.16 & 0.25 & 0.20 & 0.20 & 0.17 & 0.20 & 0.25 & 0.25 & 0.25 & 0.25 & 0.20 & 0.25 & 0.25 & 0.25 & 0.20 & 0.30 \\
\hline & $\mathrm{T}_{\text {MAX TH }}$ & 30 & 30 & 20 & 20 & 20 & 60 & 40 & 40 & 40 & 30 & 60 & 60 & 40 & 40 & 40 & 60 & 60 & 40 & 40 & 40 & 60 & 60 & 90 & 60 & 60 \\
\hline & $\mathrm{T}_{\text {MAX LT }}$ & 15 & 15 & 15 & 15 & 15 & 30 & 20 & 20 & 20 & 15 & 30 & 30 & 20 & 20 & 20 & 30 & 30 & 30 & 20 & 20 & 30 & 30 & 30 & 30 & 30 \\
\hline & $\mathrm{T}_{\mathrm{MIN}}$ & 5 & 5 & 5 & 5 & 5 & 5 & 5 & 5 & 5 & 5 & 5 & 5 & 5 & 5 & 5 & 5 & 5 & 5 & 5 & 5 & 5 & 5 & 5 & 5 & 5 \\
\hline \multirow{5}{*}{$\stackrel{\text { 뙹 }}{\sum}$} & $\begin{array}{c}\text { Delay } \\
\text { (sec/veh) }\end{array}$ & 26.9 & 27.2 & 24.8 & 19.8 & 19.5 & 45.5 & 36.5 & 27.4 & 26.8 & 25.1 & 42.8 & 41.8 & 37.7 & 27.3 & 26.4 & 50.2 & 57.1 & 45.1 & 44.5 & 43.6 & 103.9 & 91.5 & 101.6 & 100.8 & 87.0 \\
\hline & Speed (mph) & 18.9 & 18.8 & 19.4 & 20.6 & 21.0 & 15.1 & 16.7 & 18.8 & 18.9 & 19.3 & 15.6 & 15.7 & 16.5 & 18.8 & 19.0 & 14.4 & 13.4 & 15.2 & 15.3 & 15.4 & 9.3 & 10.1 & 9.5 & 9.5 & 10.5 \\
\hline & \% Stops & $64.5 \%$ & $65.5 \%$ & $67.1 \%$ & $63.2 \%$ & $61.6 \%$ & $68.6 \%$ & $67.7 \%$ & $64.7 \%$ & $64.2 \%$ & $65.1 \%$ & $71.8 \%$ & 71.2\% & $71.2 \%$ & $68.8 \%$ & $68.1 \%$ & $78.5 \%$ & $79.0 \%$ & $78.8 \%$ & 77.8\% & $77.9 \%$ & $85.1 \%$ & $84.7 \%$ & $84.6 \%$ & $84.9 \%$ & $84.2 \%$ \\
\hline & $\begin{array}{c}\text { Queue Time } \\
\text { (veh-min) }\end{array}$ & 157 & 158 & 137 & 102 & 99 & 580 & 437 & 305 & 301 & 275 & 765 & 755 & 651 & 423 & 408 & 1191 & 1384 & 1029 & 1012 & 1000 & 3593 & 2930 & 3425 & 3288 & 2782 \\
\hline & $\begin{array}{l}\text { Throughput/ } \\
\text { Demand }\end{array}$ & $99.5 \%$ & $99.4 \%$ & 99.7\% & $99.7 \%$ & $100.0 \%$ & $99.9 \%$ & $99.6 \%$ & $99.6 \%$ & $99.8 \%$ & $99.6 \%$ & $99.5 \%$ & $99.1 \%$ & $99.6 \%$ & $99.8 \%$ & $99.5 \%$ & $99.5 \%$ & $99.5 \%$ & $99.8 \%$ & $99.7 \%$ & $99.2 \%$ & $94.6 \%$ & $97.2 \%$ & 95.3\% & 95.7\% & $96.7 \%$ \\
\hline
\end{tabular}




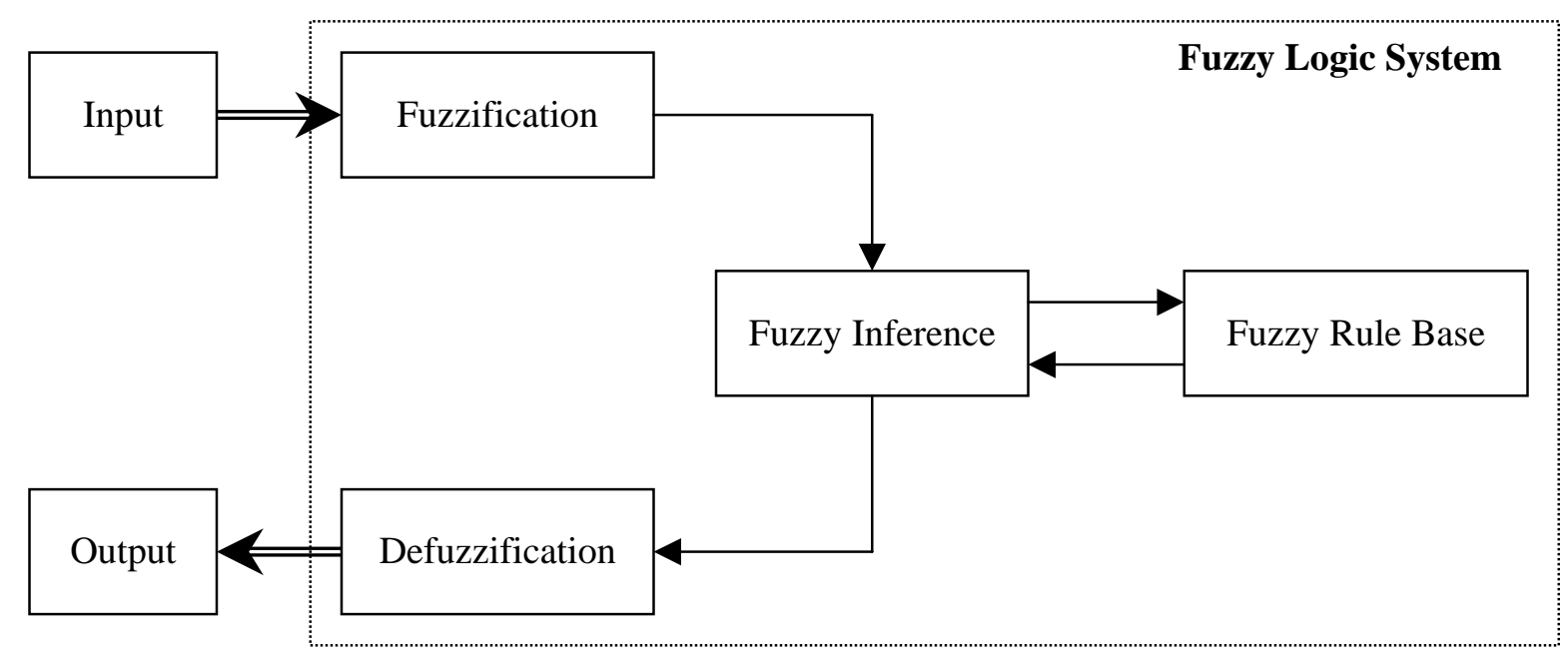

FIGURE 1. Fuzzy logic system. 


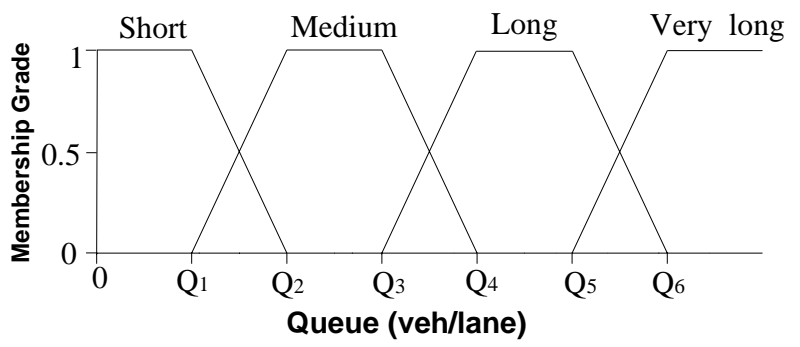

(a) Fuzzy Sets for QC and QN

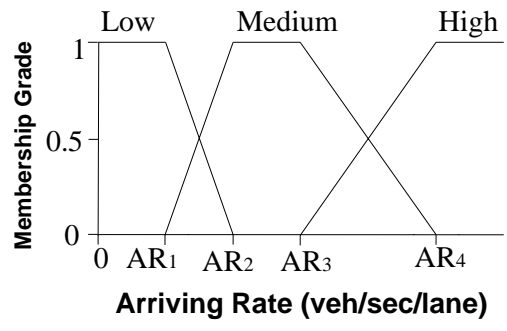

(b) Fuzzy Sets for AR

FIGURE 2. Fuzzy sets for QC, QN and AR. 


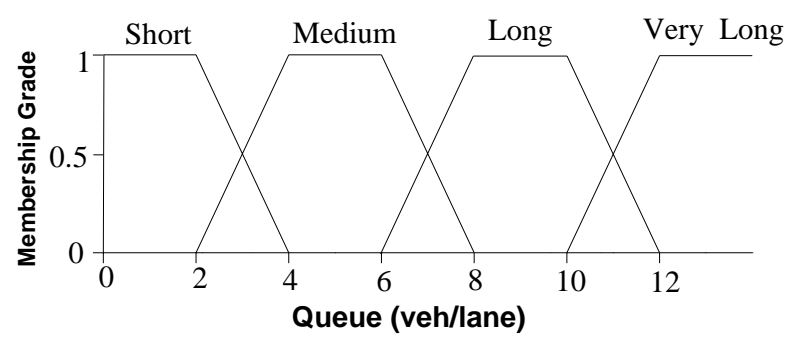

(a) Fuzzy Sets for QC and QN

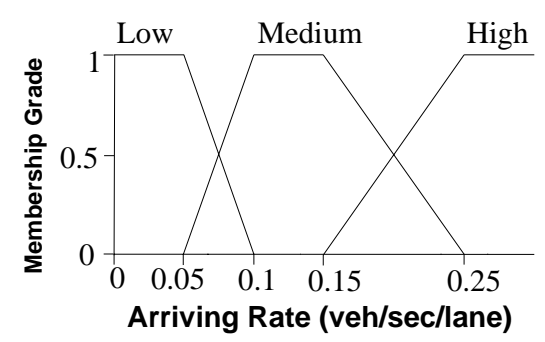

(b) Fuzzy Sets for AR

FIGURE 3. Initial threshold values for fuzzy sets for $Q C, Q N$ and $A R$. 


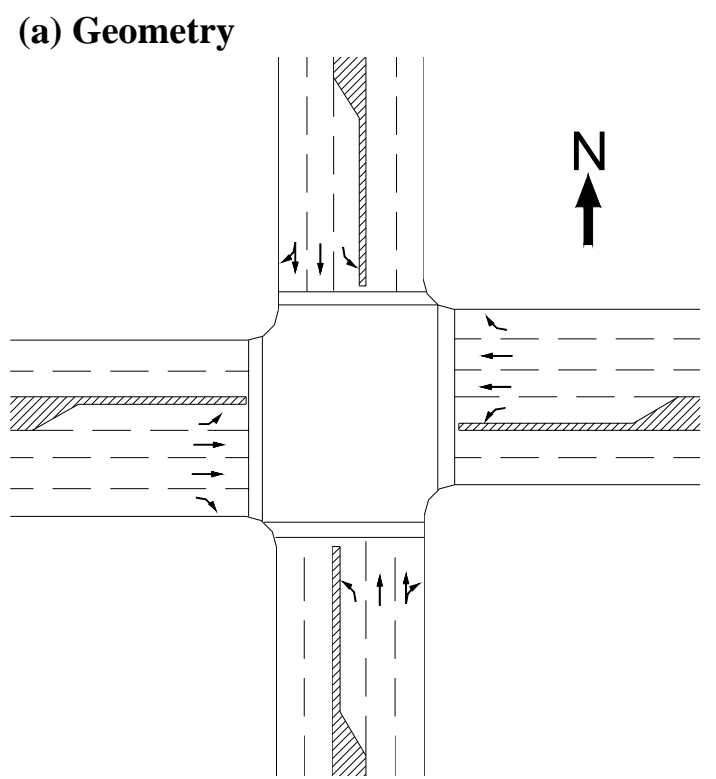

(b) Traffic Volume (veh/hr)

\section{(c) Pretimed Signal}

\begin{tabular}{|c|c|c|c|c|c|c|}
\cline { 2 - 7 } \multicolumn{2}{c|}{} & $\mathbf{2 0 \%}$ & $\mathbf{4 0 \%}$ & $\mathbf{6 0 \%}$ & $\mathbf{8 0 \%}$ & $\mathbf{1 0 0 \%}$ \\
\hline \multirow{3}{*}{ EB } & LT & 80 & 160 & 240 & 320 & 400 \\
\cline { 2 - 7 } & TH & 160 & 320 & 480 & 640 & 800 \\
\cline { 2 - 7 } & RT & 80 & 160 & 240 & 320 & 400 \\
\hline \multirow{4}{*}{ WB } & LT & 60 & 120 & 180 & 240 & 300 \\
\cline { 2 - 7 } & TH & 120 & 240 & 360 & 480 & 600 \\
\cline { 2 - 7 } & RT & 60 & 120 & 180 & 240 & 300 \\
\hline \multirow{4}{*}{ NB } & LT & 40 & 80 & 120 & 160 & 200 \\
\cline { 2 - 7 } & TH & 100 & 200 & 300 & 400 & 500 \\
\cline { 2 - 7 } & RT & 40 & 80 & 120 & 160 & 200 \\
\hline \multirow{3}{*}{ SB } & LT & 40 & 80 & 120 & 160 & 200 \\
\cline { 2 - 7 } & TH & 100 & 200 & 300 & 400 & 500 \\
\cline { 2 - 7 } & RT & 40 & 80 & 120 & 160 & 200 \\
\hline
\end{tabular}

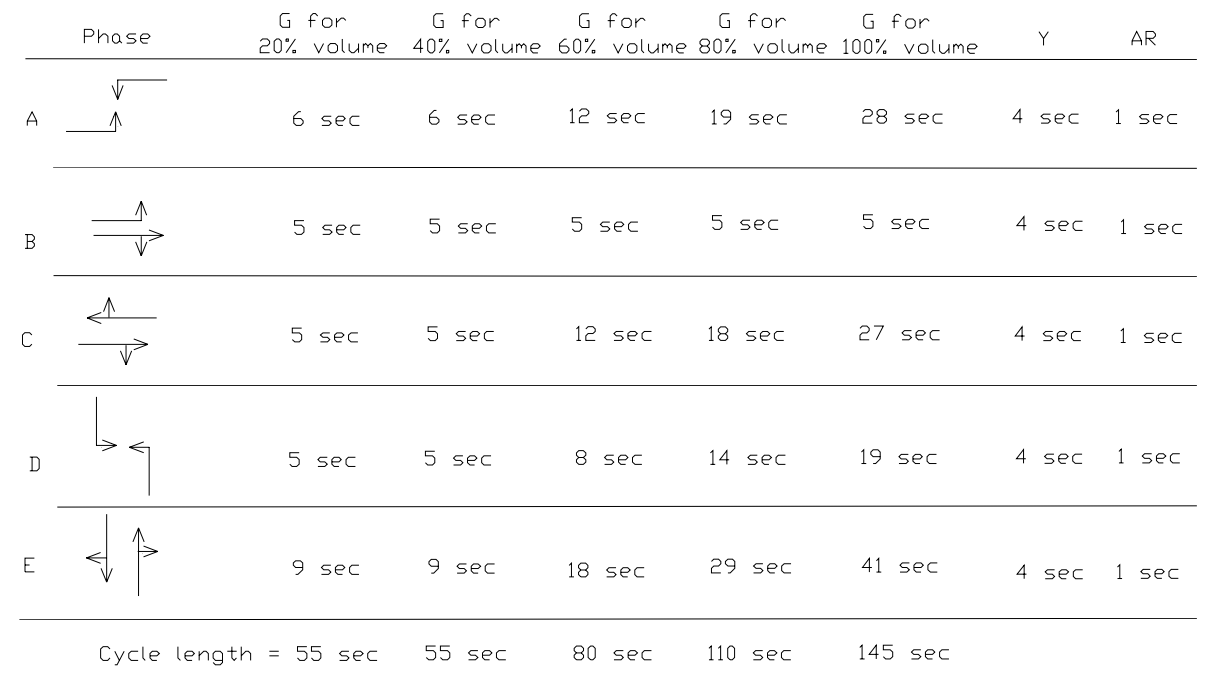

(d) Actuated Signal

FIGURE 4. Basics of signalized intersection used in case study. 


\begin{tabular}{|l|c|c|c|c|c|}
\cline { 2 - 6 } & (a) & \multicolumn{5}{c|}{ Difference } \\
\cline { 2 - 6 } \multicolumn{1}{c|}{} & Delay & Speed & $\begin{array}{c}\% \\
\text { Stops }\end{array}$ & $\begin{array}{c}\text { Queue } \\
\text { Time }\end{array}$ & Throughput \\
\hline FLC vs. Pretimed & $-42 \%$ & $21 \%$ & $-7 \%$ & $-50 \%$ & $2 \%$ \\
\hline FLC vs. Actuated & $-28 \%$ & $10 \%$ & $-2 \%$ & $-44 \%$ & $1 \%$ \\
\hline
\end{tabular}
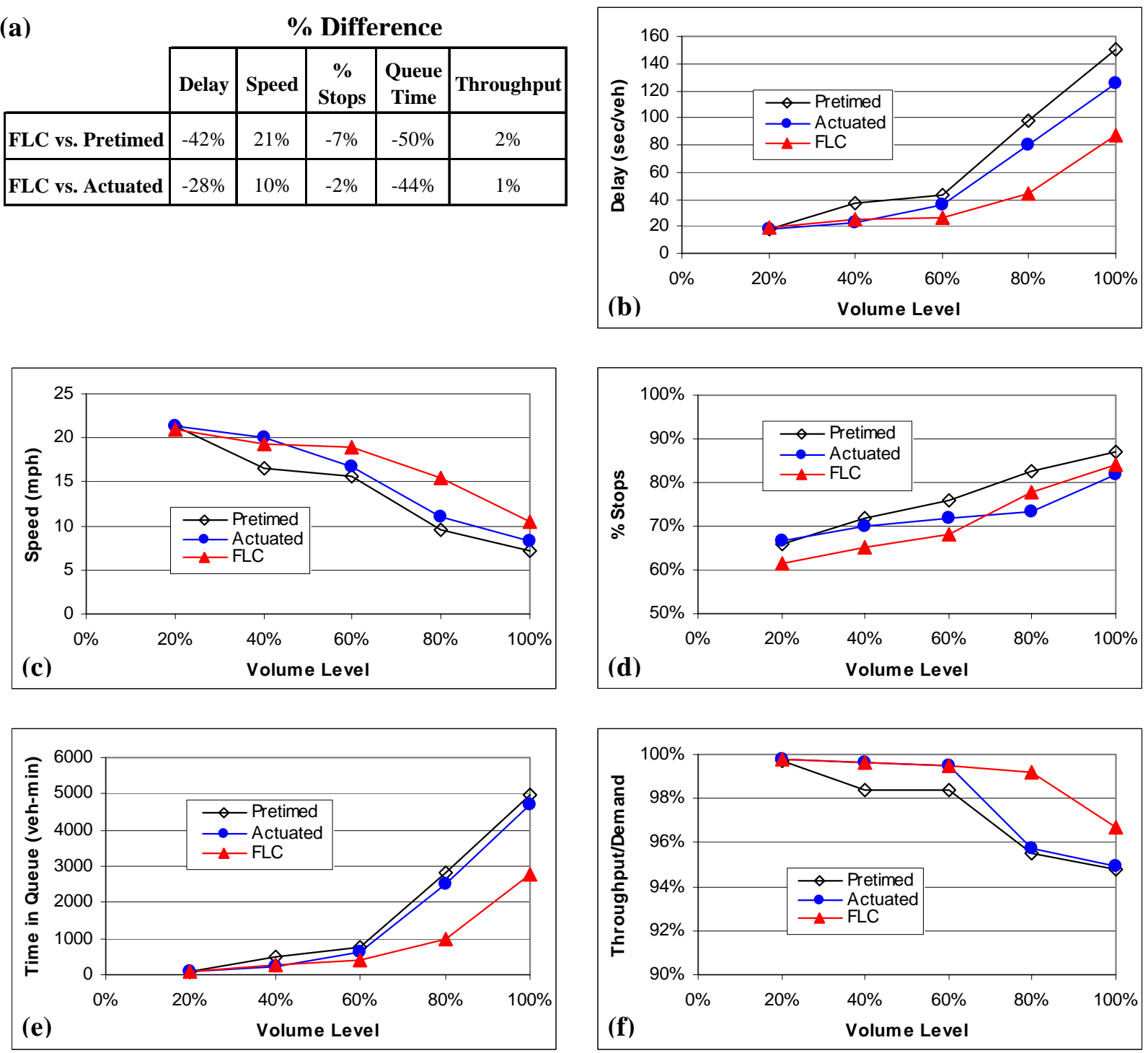

FIGURE 5. Results of case study. 